University of Nebraska - Lincoln

DigitalCommons@University of Nebraska - Lincoln

Papers in the Earth and Atmospheric Sciences

Earth and Atmospheric Sciences, Department

8-2006

\title{
Upper flow regime sheets, lenses and scour fills: Extending the range of architectural elements for fluvial sediment bodies
}

Christopher R. Fielding

University of Nebraska-Lincoln, cfielding2@unl.edu

Follow this and additional works at: https://digitalcommons.unl.edu/geosciencefacpub

Part of the Earth Sciences Commons

Fielding, Christopher R., "Upper flow regime sheets, lenses and scour fills: Extending the range of architectural elements for fluvial sediment bodies" (2006). Papers in the Earth and Atmospheric Sciences. 296.

https://digitalcommons.unl.edu/geosciencefacpub/296

This Article is brought to you for free and open access by the Earth and Atmospheric Sciences, Department of at DigitalCommons@University of Nebraska - Lincoln. It has been accepted for inclusion in Papers in the Earth and Atmospheric Sciences by an authorized administrator of DigitalCommons@University of Nebraska - Lincoln. 
Published in Sedimentary Geology 190:1-4 (August 1, 2006), pp. 227-240; doi: 10.1016/j.sedgeo.2006.05.009

Copyright (c) 2006 Elsevier B.V. Used by permission.

http://www.sciencedirect.com/science/journal/00370738

Published online June 30, 2006.

\title{
Upper flow regime sheets, lenses and scour fills: Extending the range of architectural elements for fluvial sediment bodies
}

\author{
Christopher R. Fielding \\ Department of Geosciences, 214 Bessey Hall, \\ University of Nebraska-Lincoln, Lincoln, NE 68588-0340, USA
}

\begin{abstract}
Fluvial strata dominated internally by sedimentary structures of interpreted upper flow regime origin are moderately common in the rock record, yet their abundance is not appreciated and many examples may go unnoticed. A spectrum of sedimentary structures is recognised, all of which occur over a wide range of scale: 1. cross-bedding with humpback, sigmoidal and ultimately low-angle cross-sectional foreset geometries (interpreted as recording the transition from dune to upper plane bed bedform stability field), 2. planar/flat lamination with parting lineation, characteristic of the upper plane bed phase, 3. flat and low-angle lamination with minor convex-upward elements, characteristic of the transition from upper plane bed to antidune stability fields, 4. convex-upward bedforms, down- and up-palaeocurrent-dipping, low-angle cross-bedding and symmetrical drapes, interpreted as the product of antidunes, and 5. backsets terminating updip against an upstream-dipping erosion surface, interpreted as recording chute and pool conditions. In some fluvial successions, the entirety or substantial portions of channel sandstone bodies may be made up of such structures. These Upper Flow Regime Sheets, Lenses and Scour Fills (UFR) are defined herein as an extension of Miall's [Miall, A.D., 1985. Architectural-element analysis: a new method of facies analysis applied to fluvial deposits. Earth Sci. Rev. 22: 261-308.] Laminated Sand Sheets architectural element. Given the conditions that favour preservation of upper flow regime structures (rapid changes in flow strength), it is suggested that the presence of UFR elements in ancient fluvial successions may indicate sediment accumulation under the influence of a strongly seasonal palaeoclimate that involves a pronounced seasonal peak in precipitation and runoff.
\end{abstract}

\section{Introduction}

Reconstruction of ancient alluvial channel lithosomes in terms of the formative channel style relies on the recognition of internal architectural elements and palaeoflow relationships identified from sedimentary structures and other features at a variety of scales. Despite differences in detail, most published reviews of palaeochannel characteristics advocate a similar, architectural approach (Miall, 1985, 1996; Bridge, 1993, 2003; Brierley, 1996). The inventory of architectural elements rec- ognized will, inevitably, vary as new elements are discovered and as others are perhaps combined.

To date, however, little attention has been given to architectural elements formed under upper flow regime conditions in sandy systems. This is probably for the most part because substantial deposits of interpreted upper flow regime origin have not been widely recognized in the rock record. Indeed, with the exception of flat lamination and parting lineation, upper flow regime structures are generally regarded as having low preservation potential. Plane-laminated sands 
were incorporated into Miall's (1985) architectural element scheme as "Laminated Sand Sheets", but it was suggested that such elements were likely confined to flashy discharge streams such as characterized desert environments, and by extension not to the deposits of larger fluvial systems. Nonetheless, Miall (1985) suggested that such elements range up to $2.5 \mathrm{~m}$ thick and $>100 \mathrm{~m}$ long, and can be stacked into thicker, discrete vertical successions.

Examples of upper flow regime bedforms found preserved in modern alluvial channels seem to fall into two categories: 1) those found in shallow flows that can readily approach or exceed Froude numbers of unity (e.g., Langford and Bracken, 1987), and 2) those found in rivers characterized by extreme variations in discharge, and specifically rapid drops in water level on the falling limb of the hydrograph of major flow events, which can allow preservation of upper flow regime bedforms and sedimentary structures without significant modification (e.g., McKee et al., 1967; Shaw and Kellerhals, 1977; Sneh, 1983; Blair, 1987; Alexander and Fielding, 1997). Few examples have been described from either the modern or ancient where such upper flow regime structures dominate large-scale geomorphic/architectural elements (but see McKee et al., 1967; Picard and High, 1973; Tunbridge, 1981, for examples). Furthermore, several authors have pointed out ambiguities between the distinguishing criteria for upper flow regime structures and those for combined wave-current flow structures such as hummocky crossstratification (e.g., Rust and Gibling, 1990a; Cotter and Graham, 1991; Alexander et al., 2001). The reader is referred to Bridge (2003) for a more detailed review of bedforms and resultant sedimentary structures in fluvial environments.

In this paper, the current understanding of upper flow regime bedforms and sedimentary structures from empirical data derived mainly from flume tank experiments is briefly reviewed, in order to try to facilitate interpretation of the ancient. A spectrum of sedimentary structures from the rock record is then described, and placed in a hydrodynamic context. It is suggested that such structures can in certain circumstances form discrete architectural elements, and modification of Miall's (1985) "Laminated Sand Sheets" architectural element to an "Upper Flow Regime" architectural element is proposed. Some examples of this more broadly-defined element, and its depositional context, are described and interpreted. It is suggested that where developed, this newly-defined architectural element may be indicative of strongly seasonal climate regimes with pronounced seasonal peaks in precipitation and runoff, and that it may therefore have palaeoclimatic utility.
2. Transitional upper flow regime and upper flow regime structures

\subsection{A review of current understanding based on flume studies}

Our understanding of bedforms and resultant sedimentary structures from unidirectional current flows derives in large part from a variety of experimental studies conducted in mainly small-scale flume tanks (e.g., Kennedy, 1963; Harms et al., 1975; Allen, 1982; Southard and Boguchwal, 1990). The factors that determine the formation of various bedforms are complex, but with certain variables fixed (flow depth, temperature), bedform stability fields can be plotted as a function of flow strength or velocity against grain size. At low flow velocities beyond the initial threshold for grain movement, cross-sectionally asymmetrical ripples are the ubiquitous product for finer sands. For coarser-grained sediment, greater flow power is required to move particles, which initially form a lower plane bed phase and with increasing flow strength transform into dunes, larger asymmetrical bedforms. At higher flow strengths, termed the upper flow regime, dunes and ripples become washed out to form an upper plane bed, and at still higher flow velocity antidunes are formed. A further bedform condition, termed chute and pool, is also known from flume experiments but not typically shown on bedform stability diagrams owing to the extreme high flow powers required for their formation. Note that for larger grain sizes, dunes may pass directly into the antidune stability field with increasing flow velocity.

Bedform stability diagrams are useful for visualizing the range of bedforms possible for different combinations of conditions, but complicating this is the fact that bedform transformation lags flow conditions in both nature and experimental flows. It follows that if the rate of change of flow strength is rapid, then bedforms may not be able to equilibrate with these rapidly changing conditions, even in strong flows where more sediment is mobile. Thus, in gradually changing flows, the bedforms most likely to be preserved are those formed under the most tranquil conditions since bedforms will have adequate time to adjust to the slowly falling flow conditions. Conversely, in rapidly changing flows there is much greater potential for preserving bedforms characteristic of strong flow as the rapid rate of fall in stream power leads to a disequilibrium between flow and bed conditions. For example, on the beds of rivers that experience massive seasonal variation in discharge such as the Burdekin River of northeast Australia, very rapid rise and fall of the hydrograph during major flow events allows formation and 

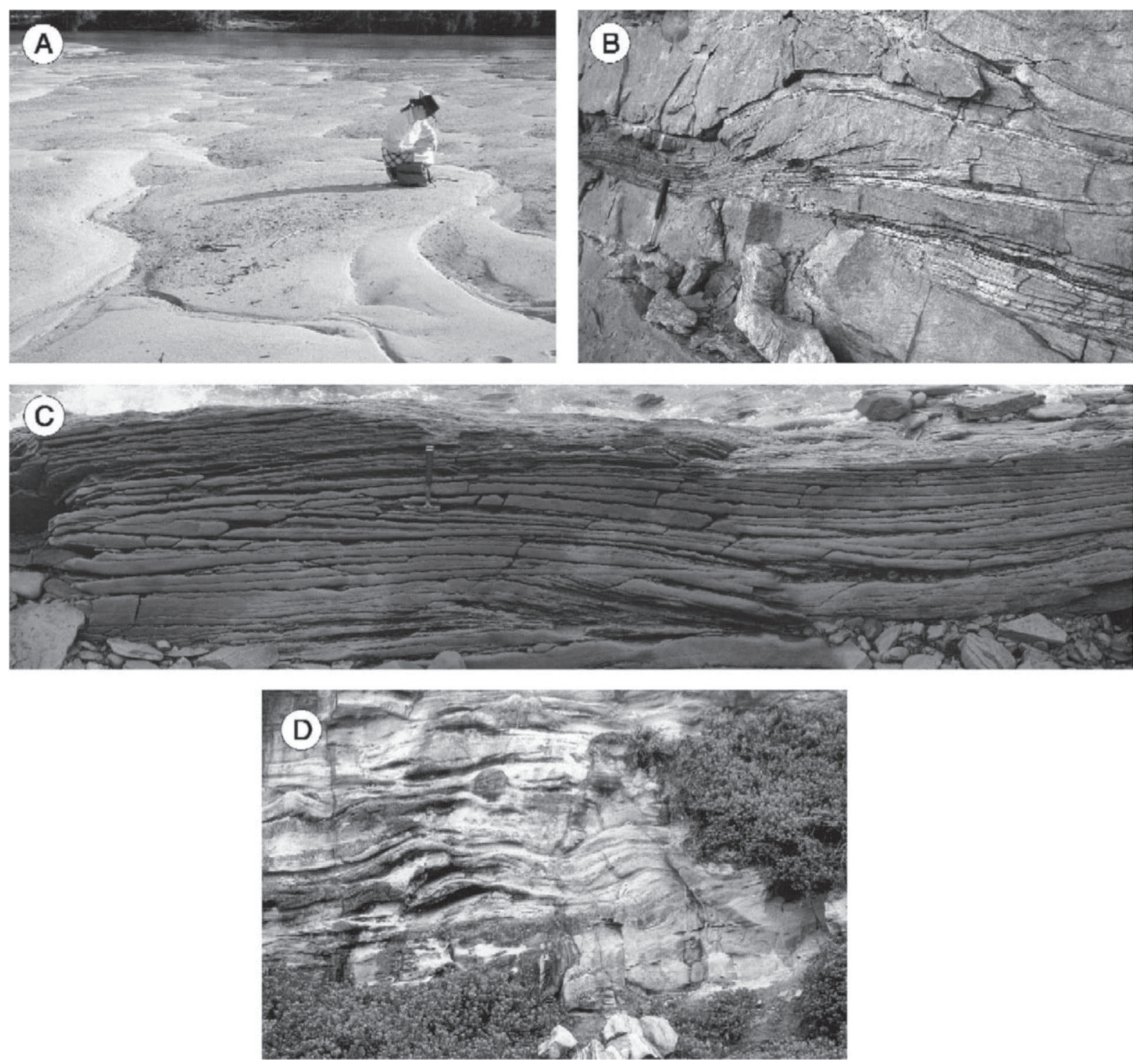

Figure 1. Photographs of cross-bedding structures considered representative of the transition from dune to upper plane bed phase. A) Small-scale, washed out dunes, showing flat, eroded tops. Modern Burdekin River, northeast Australia, flow from left to right. B) "Humpback cross-bedding" set, showing preservation of the complete bedform, reworking of the stoss side by small dunes or ripples, sigmoidal foreset geometry and flattening out of the lee side into an extensive bottomset. Late Permian Bainmedart Coal Measures, Prince Charles Mountains, Antarctica. Flow from right to left. Hammer 0.3 m. The external and internal cross-sectional geometry suggest deposition from a waning flow. C) Example of humpback cross-bedding transitional to flat lamination, showing flattening out of foreset bedding downdip and upward through the set, culminating in a convex upward (hummocky) bedform. Late Carboniferous South Bar Formation, Victoria Mines, Nova Scotia, Canada. Flow from left to right. Hammer $0.3 \mathrm{~m}$. D) Enigmatic structures that resemble dune-scale cross-bedding climbing at a supercritical angle, and passing transitionally upward into convex-upward beds that may be antidunal. Late Permian Newcastle Coal Measures, Little Beach, NSW, Australia. Flow from right to left, c. $5 \mathrm{~m}$ section illustrated.

preservation on the river bed of gravelly antidunes (Alexander and Fielding, 1997).

Although upper flow regime bedforms are widely known from flume experiments, sedimentary structures arising from such conditions are regarded as having low preservation potential in the rock record, with the exception of upper plane bed flat lamination. How- ever, it follows from the above that in facies deposited under climatic regimes that were characterized by strongly seasonal precipitation and hence discharge distribution, such upper flow regime sedimentary structures might have a greater chance of preservation. It is suggested that in fact upper flow regime sedimentary structures are moderately well-represented in the geo- 
logical record, are considerably more widespread than is generally perceived, and are probably unnoticed or ignored in many cases. One of the key issues in the recognition of these structures is that although upper flow regime bedforms can occur on a wide variety of scales, knowledge of their formation is restricted to the small scale that can be achieved in flume tank experiments. Thus, most geologists have few if any analogies to draw on in considering possible large-scale, upper flow regime structures. In the following passages, examples are documented from a spectrum of sedimentary structures, both small-scale and large-scale, that are interpreted in terms of progressively increasing flow strength. Analogy is drawn with results of flume experiments where possible.

\subsection{Sigmoidal to low-angle cross-bedding ("humpback cross-bedding")}

At flow conditions transitional from the dune stability field into the upper plane bed field, dunes typically become "washed out" as the tops are planed off (Figure 1A), and this is reflected in changes to the cross-sectional geometry of resultant cross-bedding. Flume experiments (e.g., Saunderson and Lockett, 1983; Bridge and Best, 1988; Hand and Bartberger, 1988) and well-exposed ancient analogues (e.g., Chakraborty and Bose, 1992) suggest that as the dune-upper plane bed transition is approached with increasing flow power, dune cross-sets transform from a predominantly concave-upward to a sigmoidal geometry in cross-section, with discrete topset, foreset and bottomset elements. Saunderson and Lockett (1983) noted three types of bedform that were seen to coexist: 1 . asymmetrical dunes, which produced conventional, foreset-dominated cross-bedding, 2. symmetrical dunes, which produced convexupward cross-bedding, and 3. humpback dunes, which produced cross-bedding with a sigmoidal profile involving topset, foreset and bottomset.

Examples of all three styles can be recognized in ancient examples (e.g., Figure 1B, C). In some cases, the topset appears to define a bed of planar-laminated sand, which grades down-current or down-palaeocurrent into the relatively low-angle foreset and in turn into an extensive, flat-laminated bottomset (e.g., Figure 1C). In other examples, some convex-upward bed topography is preserved at the top of the set (constituting a form set), implying preservation of the formative bedform more or less intact (e.g., Figure 1B).

Humpback cross-bedding and the associated styles of cross-bedding described above have been recognized in a variety of ancient fluvial successions (e.g., Røe, 1987; Røe and Hermansen, 1993; Browne and Plint, 1994;
Fielding and Webb, 1996) and are generally interpreted as recording the transition from dune to upper plane bed stability conditions, or vice versa. The preservation of a generally flat-laminated (upstream) topset in some examples (e.g., Figure 1A) implies formation under rising flow power conditions. In other cases, the absence of a significant topset or erosional contacts with small cross-sets, and preservation of an extensive, flat-laminated bottomset, might suggest formation under falling flow power (e.g., Figure 1B). Preservation of these crossbedding structures within cross-bedded and flat-laminated sandstone intervals must therefore reflect fluctuating flow conditions within the formative streams. Note that although the primary control on these structures in fluvial environments is likely to be flow stage (and therefore depth and velocity), deconvolving these and other variables will not generally be possible. It is, nonetheless, possible to interpret the spectrum of crosssectional geometry from sigmoidal cross-bedding, through true humpback cross-bedding, to low-angle, asymptotically based cross-bedding as reflecting the progressive planing off ("washing out") of dunes under increasing flow power (Figure 1A-C).

A further, related variety of cross-bedding is shown in Figure 1D, in which cross-sets, some of the humpback form while others seem to define drapes over immediately underlying strata, appear to be climbing at a critical to supercritical angle. This geometry is reminiscent of extreme supercritically climbing ripples (Allen, 1982), termed "sinusoidal ripples" by Jopling and Walker (1968), but to the author's knowledge has not been previously described from dune-scale structures. Sinusoidal ripples are formed under rapid fallout of large quantities of sand from near-bed suspension. The figured examples are preserved within $1 \mathrm{~m}$ of the base of a $20 \mathrm{~m}$ thick sandstone- and conglomerate-filled fluvial channel deposit. Accordingly, this supercritically climbing humpback cross-bedding is interpreted as recording dune to upper plane bed transition conditions under massive rates of sediment fallout, most likely associated with rapid fall of flow stage during sediment aggradation in the formative channel.

\subsection{Flat/planar bedding}

Although a lower flow regime plane bed stability field exists for very coarse sand and coarser grain sizes (e.g., Harms et al., 1975; Allen, 1982; Southard and Boguchwal, 1990), most preserved examples of flat and planar bedding in sands and sandstones (particularly in very fine- to medium-grained sands) are thought to reflect the upper plane bed field. This is particularly so for structures that preserve an associated parting lineation 

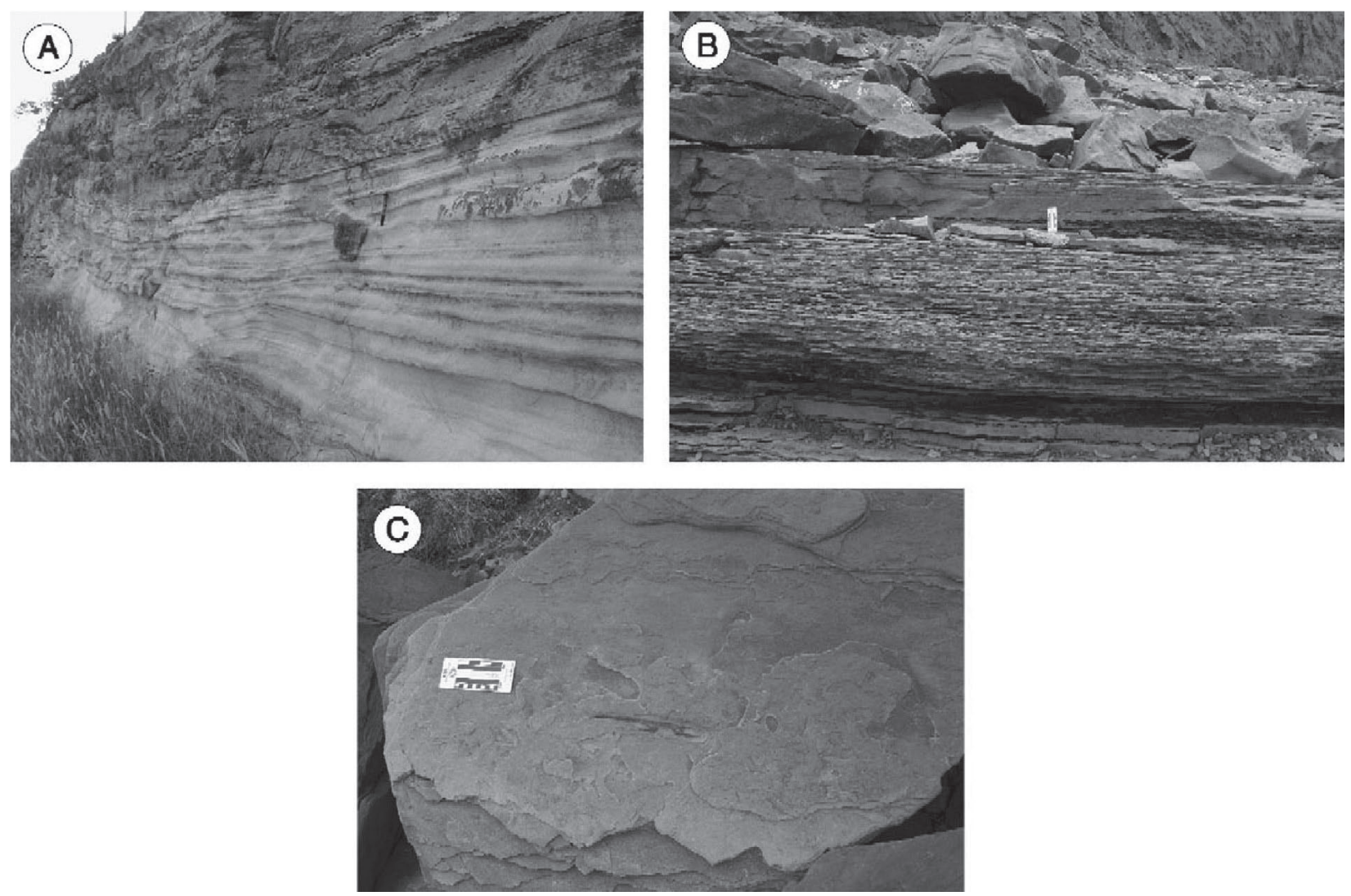

Figure 2. Photographs of sedimentary structures of interpreted upper plane bed origin. A) Interval of flat-laminated sandstone with minor undulations and discordances, passing upward into a very low-angle cross-bed the foresets of which flatten out downdip into flat lamination. Late Permian Colinlea Sandstone, west of Springsure, Queensland, Australia. Flow from left to right. Marker pen $0.15 \mathrm{~m}$. B) Interval of flat-laminated, fine-grained sandstone (flaggy appearance) passing upward into very low-angle cross-bedded sandstone. Late Carboniferous Joggins Formation, Joggins, Nova Scotia, Canada. Sense of flow uncertain. Scale card $0.16 \mathrm{~m}$. C) Bedding plane view of flat lamination with parting lineation, indicating sense of flow. Note alignment of plant stem fragment with parting lineation (sense of flow left-right). Late Carboniferous Joggins Formation, Joggins, Nova Scotia, Canada. Scale card $0.16 \mathrm{~m}$.

or "primary current lineation" (Figure 2), thought to be the result of microvortices acting under high stream powers to sort and deposit sand grains (Allen, 1982). More recently, experimental data have allowed Bridge and Best (1988), Paola et al. (1989), Cheel (1990), and Best and Bridge (1992) to propose that plane bedding is formed by the migration of low-amplitude bed waves across a flat surface. Evidence for such a process is typically preserved only at the lamina scale as small-scale textural variations and low-angle discordant surfaces.

It is not necessary to elaborate significantly on this sedimentary structure here, as it is widely described in the literature, and its interpretation is well-established. Some variations to plane bedding are, however, worthy of note. Various authors have described minor, low-angle discordant bedding (Figure 2A, B) within predominantly planar-bedded sands and sandstones, both from the modern (e.g., McKee et al., 1967; Stear, 1985) and ancient (e.g., Tunbridge, 1981; Cotter and Graham, 1991;
Browne and Plint, 1994). This is at a considerably larger scale than the low amplitude bed wave structures noted above. A variety of interpretations have been offered for such structures, including partial preservation of dunes as low-angle cross-bedding, migration of macroforms and partial preservation of different elements separated by erosion surfaces, and partial preservation of antidunes or transitional plane bed-antidune features. The last of these alternatives is explored further below.

\subsection{Planar bedding associated with low-angle cross- bedding and convex-upward bedding}

Some fluvial sandstone bodies preserve an association of mainly low-angle to planar bedding structures that are not readily interpreted purely in terms of plane bed conditions (Figure 3). These bodies display a "flaggy" appearance at outcrop, and comprise complex interbedding 

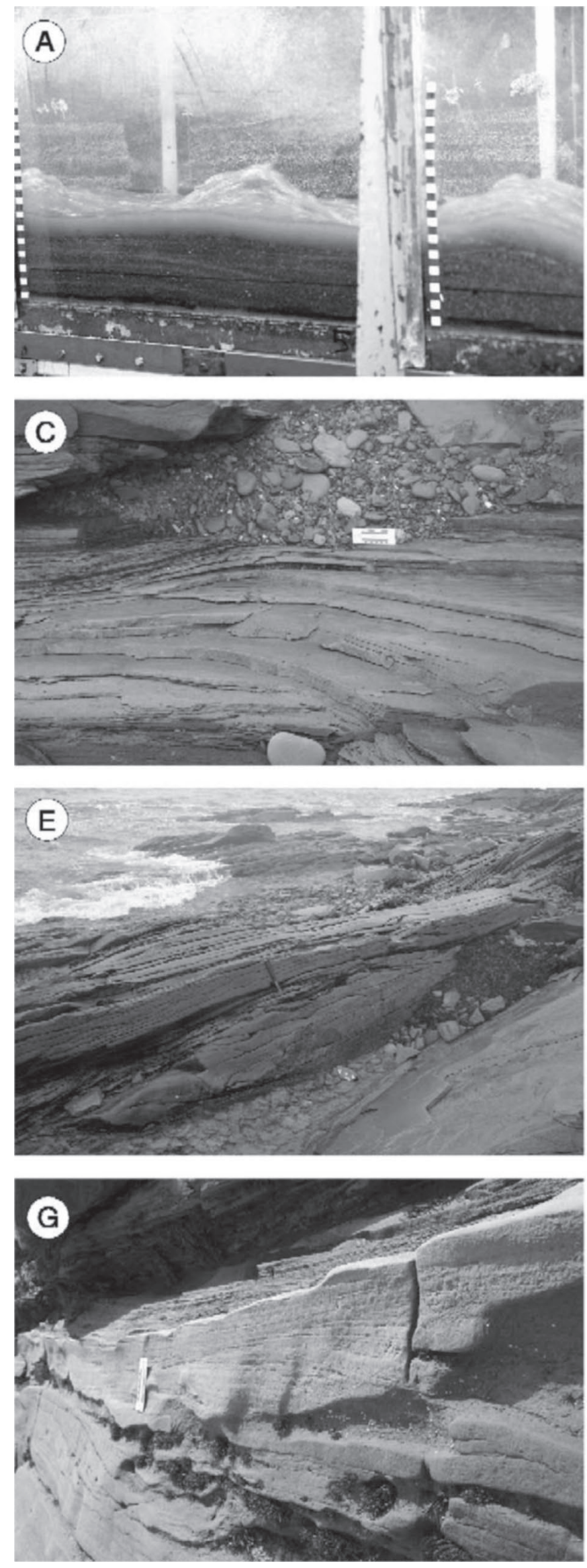
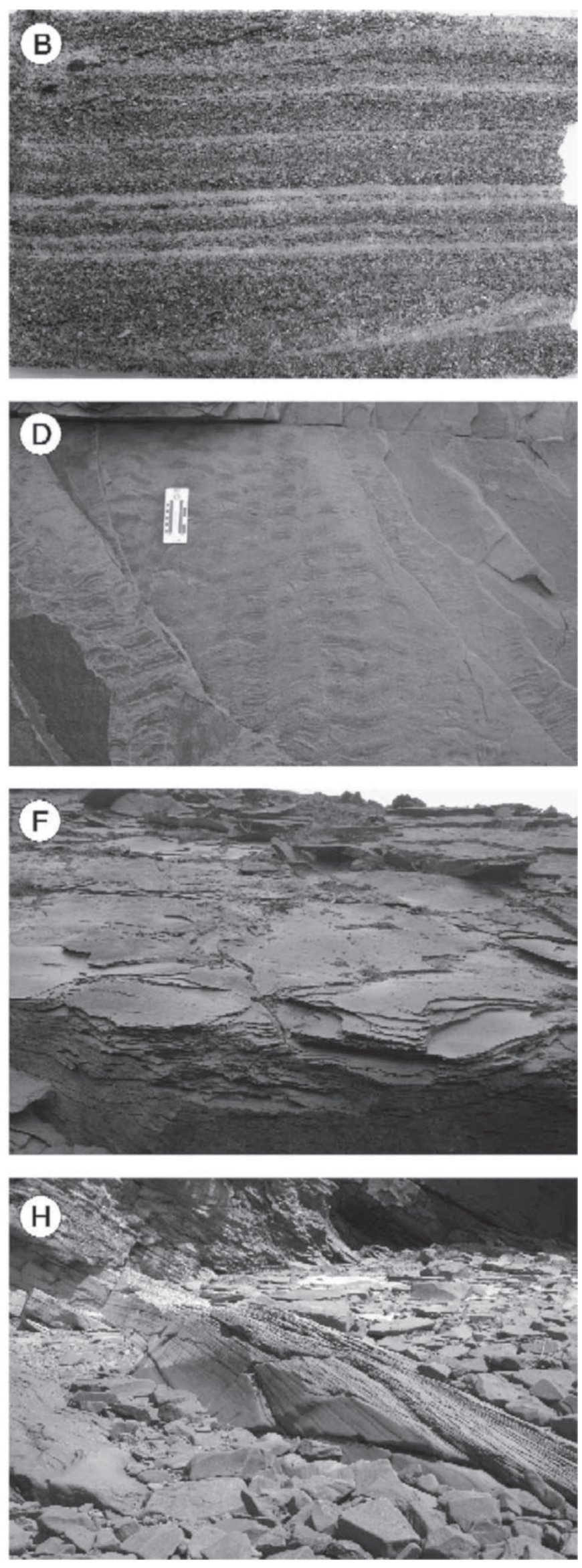
of flat/planar bedding, low-angle, strongly top-truncated cross-bedding with typically asymptotic basal laminae that flatten downdip into planar lamination, and concave-upward to convex-upward bedding with internal cross-strata that in a few cases dip in an up-palaeocurrent direction but in most dip down-palaeocurrent (Figure 3E). Large-scale equivalents of these structures have also been described from pyroclastic (e.g., Schmincke et al., 1973) and subglacial outwash (e.g., Brennand, 1994; Russell and Arnott, 2003) deposits. These structures are considered distinct from the "symmetrical dunes" formed experimentally by Saunderson and Lockett (1983) and from the very small-scale bed waves found by Bridge and Best (1988), among others. They may, however, be analogous to the "in-phase wave horizontal lamination with in-phase wave foreset cross-laminae" noted in flume experiments by Cheel (1990) at flow strengths transitional into the antidune bedform stability field. Associations of structures such as this have also been produced experimentally at a small scale by Alexander et al. (2001) under upper flow regime conditions. In the rock record, smallscale associations such as those produced by Alexander et al. (2001) could easily be confused with, or interpreted as, small-scale dune cross-bedding, but the larger-scale structures illustrated in Figure 3 cannot be as readily explained in such a way.

This association of sedimentary structures is interpreted as arising predominantly from flows that are transitional from the upper plane bed to antidune stability fields, or that fluctuate from one to the other. The majority of sedimentary structure seems to indicate plane bed conditions, but some features suggest higher stream powers. Upstream-dipping cross-bedding (or "backset" bedding) seems to be a characteristic of upper flow regime conditions, specifically within the antidune and chute and pool stability fields (Jopling and Richardson, 1966; Harms et al., 1975; Alexander et al., 2001; Breakspear, unpublished data: Figure 3A, B). Examples have been described from the ancient by Cotter and Graham (1991) and Browne and Plint (1994), among others, and interpreted in ways that are compatible with this hypothesis.

\subsection{Convex-upward bedding with backset cross-bed- ding and symmetrical drape lamina sets}

Some modern fluvial environments preserve antidune bedforms (e.g., Shaw and Kellerhals, 1977; Langford and Bracken, 1987; Alexander and Fielding, 1997), and antidune structures have been extensively produced by experimental flows under standing waves (e.g., Kennedy, 1963; Middleton, 1965; Jopling and Richardson, 1966; Harms et al., 1975; Cheel, 1990; Alexander et al., 2001; Breakspear, unpublished data: Figure 3A, B). These observations and experimental data show that the sedimentary structures produced by antidunes vary considerably in plan and cross-sectional geometry. Bedding structures known to be produced by antidunes include truncated trough cross-bedding inclined upstream or downstream, and convex-upward, constructional features with symmetrical or near-symmetrical, external form-concordant lamination (Figure 3A, B). Furthermore, since antidune wavelength is scaled to water depth (Kennedy, 1963), a range of scale is possible in nature beyond what is known from small-scale flume experiments.

Fluvial sandstone bodies that contain convex-upward bedding structures have proved historically difficult to interpret, invoking confusion with hummocky cross-stratification (e.g., Rust and Gibling, 1990a; Cotter and Graham, 1991). Nonetheless, these and other authors have used the occurrences of symmetrical or near-sym-

Figure 3. Photographs of sedimentary structures interpreted to record transitional plane bed - antidune and antidune bedforms. A) Standing waves in a flume experiment, with upstream-dipping antidune bedding below. Flow from left to right. Scale bar in $\mathrm{cm}$. Photo courtesy of Richard Breakspear. B) Lacquer peel showing plane bed and upstream-dipping antidune (near base of photo) lamination from a flume experiment (velocity $=1.5 \mathrm{~m} / \mathrm{s}$, flow depth $=5 \mathrm{~cm}$, Froude number $=2.05$, aggradation rate $=6 \mathrm{~mm} / \mathrm{min})$. Flow was from left to right. Field of view $30 \times 18 \mathrm{~cm}$. Photo courtesy of Richard Breakspear. C) Small, convexupward cross-bed in cross-section. Note progressive increase in convexity upward through the bed. Late Carboniferous South Bar Formation, Victoria Mines, Nova Scotia, Canada. Flow direction unknown. Scale card $0.16 \mathrm{~m}$. D) Bedding plane view of the structure shown in C), showing a form set of slightly sinuous-crested, ripple-scale bedforms that in cross-section show very low-angle cross-lamination or no internal structure. These are tentatively interpreted as the product of low-amplitude bed waves, sensu Bridge and Best (1988) and others. Note also parting lineation in the upper right of the view. Interpreted flow direction from top to base. Scale card $0.16 \mathrm{~m}$. E) Bedset displaying low-amplitude, convex-upward, low-angle cross-bedding interpreted as a transitional antidune structure. Late Carboniferous South Bar Formation, Victoria Mines, Nova Scotia, Canada. Flow from left to right. Hammer $0.3 \mathrm{~m}$. F) Oblique bedding plane view of interpreted three-dimensional antidunes (Rust and Gibling, 1990a) from the same locality as C) and D). Flow direction unknown. Width of view $4 \mathrm{~m}$. G) cross-sectional view of convex-upward, low-angle cross-bedding showing a lower bed (by scale card) that is dominated by foreset bedding, an overlying bed dominated by backset bedding and an uppermost bed preserving a down-palaeocurrent-descending, low-angle foreset.. Mid Carboniferous Shepody Formation, Downing's Cove to Boss Point, Nova Scotia, Canada. Flow from right to left. Scale card 0.16 m. H) Large-scale, convexupward bedding structure interpreted as the deposit of a large antidune. Note the largely symmetrical nature of bedding about the axis. Two intact bedforms were found at the horizon, crests spaced $24 \mathrm{~m}$ apart. Upper Carboniferous Boss Point Formation, Boss Point, Nova Scotia, Canada. Flow direction from bottom right to top left. About $2 \mathrm{~m}$ vertical section shown. 

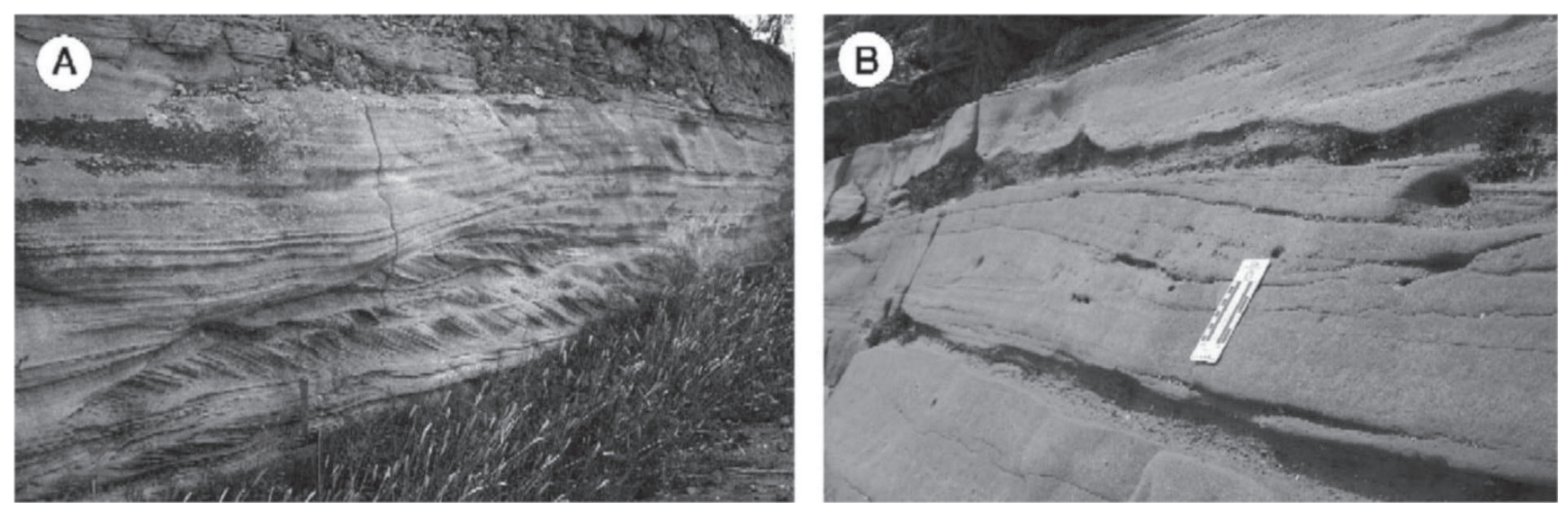

Figure 4. Photographs of possible chute and pool structures. A) Prominent, upstream-dipping truncation surface cutting crossbedded sandstones, overlain by flat and low-angle lamination, the lower parts of which define a low-angle backset and the upper parts of which pass convexly over topographic high downstream of the scour, beds expanding downstream. The scour is interpreted as a possible pool and the topographic high to the right is a possible chute. A series of these features is preserved with semi-regular wavelength (see Figure 6B). Late Permian Colinlea Sandstone, west of Springsure, Queensland, Australia. Flow from left to right. Hammer $0.3 \mathrm{~m}$. B) Backset in fine to medium-grained sandstone, interpreted as associated with an antidune or chute and pool. Flow direction from adjacent cross-bedding right to left. Mid Carboniferous Shepody Formation, Downing's Cove to Boss Point, Nova Scotia, Canada.

metrical, convex-upward bedforms in association with structures of unequivocal unidirectional current origin to discount a combined flow origin and to suggest formation under the antidune stability field in fast-flowing streams. In some cases, it may be difficult to separate antidune-related cross-bedding from dune cross-bedding, in the absence of other bedding styles. However, several distinctive bedding styles are here considered representative of antidunal (or transitional antidunal) conditions.

Small-scale antidunes have been identified from several fluvial successions (Figure 3C, F), including the Carboniferous South Bar and Boss Point Formations of Nova Scotia (Rust and Gibling, 1990a; Browne and Plint, 1994, respectively). In cases where the plan geometry is preserved, the bedforms appear to be strongly three-dimensional (Figure 3F; e.g., Rust and Gibling, 1990a). Parting lineation is abundant on bedding planes. A further common feature on the bedding planes of these flaggy sandstones, noted by Browne and Plint (1994, their Figure 19), are trains of low amplitude (1-3 mm), slightly sinuouscrested ripples and associated very low-angle cross-lamination (Figure 3D). These may be the product of the lowamplitude, millimeter-scale bed waves believed to be active during formation and migration of antidunes (Alexander et al., 2001), and may be related to the "rhomboid ripples" of Allen (1982). A further associated feature noted by the author in the South Bar Formation and in an upper Pennsylvanian channel body in Kansas is the presence of discrete, $<5 \mathrm{~cm}$ thick, intervals of apparently structureless, poorly-sorted sandstone interbedded with cleaner, well-sorted, cross-stratified and antidunebearing sandstones. The structureless beds are tabular over the extent of outcrops (10-30 m) or in some cases are truncated by an overlying bed. Their origin is enigmatic, but one possible interpretation given their context is that they record the abrupt breaking of standing waves and en masse deposition of the full size range of particles held by the flow, in a manner similar to that described experimentally by Alexander et al. (2001).

Larger-scale equivalents of the structures described above have also been noted by the author in several formations of interpreted fluvial origin (Figure 3G, H). The range of internal structure appears similar in all respects to their small-scale counterparts. The amplitude, and where measurable, wavelength of these structures, however, suggest that they were formed under significantly deeper water. One example noted in the Boss Point Formation at Boss Point, Nova Scotia, exhibited two intact, near-symmetrical bedforms (Figure $3 \mathrm{H}$ ) within the same bed, approximately $24 \mathrm{~m}$ apart from crest to crest in an orientation that from adjacent crossbedding was close to along-palaeoflow. Rearranging the Kennedy (1963) equation (see Alexander and Fielding, 1997) allows an estimate of 4-5.5 $\mathrm{m}$ for the depth of water in which the bedforms were active, and a formative flow velocity of c. $6 \mathrm{~ms}^{-1}$. This is compatible with water depth estimates from adjacent large-scale crossstrata, using the methodology of Leclair and Bridge (2001). Again, the internal structure is distinct from the "symmetrical dunes" noted by Saunderson and Lockett (1983), but quite similar to the "type IV dunes" of Schmincke et al. (1973) and to low-angle, cross-stratified bedsets described by Russell and Arnott (2003) that were both interpreted as antidune deposits. 


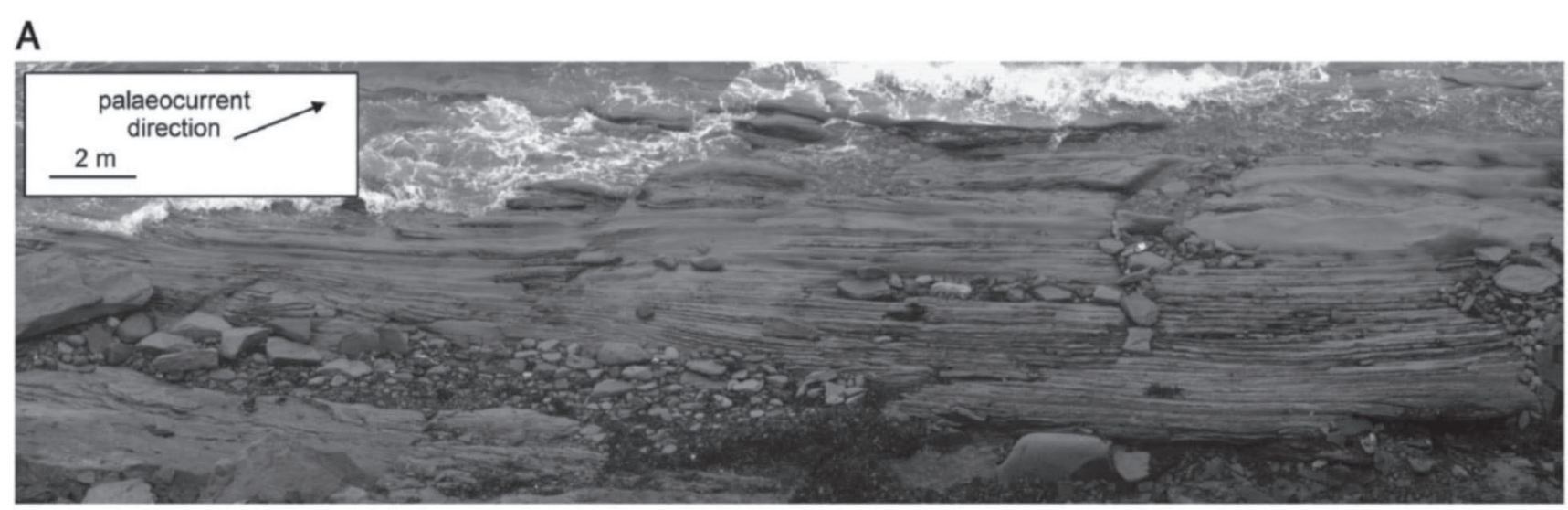

B
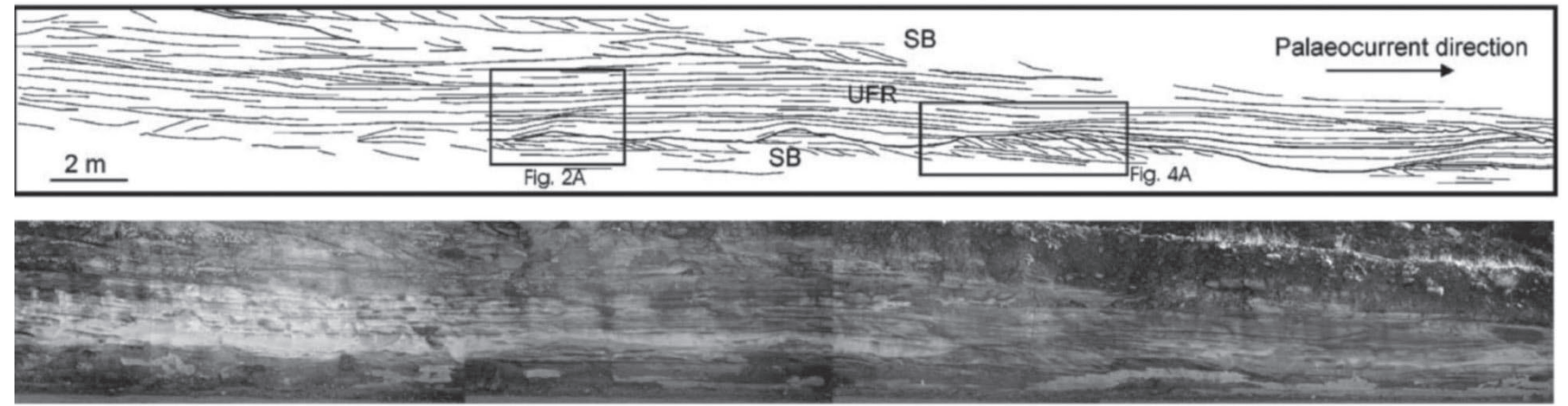

Figure 5. Views of the proposed UFR architectural element in two outcrop examples. A) view of sandstone body dominated by flat and low-angle lamination and bedding, with minor-concave upward and convex-upward forms. Late Carboniferous South Bar Formation, Victoria Mines, Nova Scotia, Canada. Width of view c. 30 m. B) Photomosaic and interpreted line drawing showing the detail of an UFR element underlain and overlain by cross-bedded sandstones (Miall's, 1985 "SB" - Sandy Bedform element). Note the prominence of regular scours and intervening highs (possible chute and pool structure), flat, low-angle and convex-upward bedding. Late Permian Colinlea Sandstone, west of Springsure, Queensland, Australia. Flow from left to right. Areas shown as close-ups in Figures 2 and 4 are boxed.

\subsection{Backsets associated with an upstream-dipping scour surface}

The most extreme depositional bedforms known from natural flows and experiments are termed chute and pool structures (e.g., Simons et al., 1963; Jopling and Richardson, 1966; Alexander et al., 2001). These are typically upstream-dipping cross-beds, or backsets, that lap downstream onto an upstream-dipping scour surface. This cross-sectional geometry arises because chute and pool structures are formed at a hydraulic jump where shallow, fast-flowing water (the chute) passes abruptly into deeper, less fast-flowing water (the pool).

Chute and pool structures are virtually unknown from fluvial strata owing to their presumed low preservation potential, and indeed most published examples of chute and pool structures come from the deposits of explosive volcanic eruptions, such as the spectacular Pleistocene section at Laacher See, Germany (Schmincke et al., 1973). The sole, published ancient example of chute and pool structure known to the author is a se- ries of small-scale structures from Precambrian rocks in Canada (Fralick, 1999). Here, another, larger-scale bedset of interpreted chute and pool origin is described from the Permian of central Queensland, Australia, and a further, possible example from the Shepody Formation of Nova Scotia is provided.

The first example lies within a sandstone body of interpreted fluvial origin, in the early Late Permian Colinlea Sandstone of the Springsure Shelf, Queensland, Australia, a structural corridor linking the partially contiguous Galilee Basin to the west with the Bowen Basin to the east (Fielding et al., 2000; and see Fielding et al., 1996 for locality description). Within the lower part of the body, a scour surface c. $0.75 \mathrm{~m}$ deep is seen to be inclined in an up-palaeocurrent direction, as established from small-scale cross-beds immediately beneath this feature (Figure 4A). The scour is filled by lamina sets that lap up onto the scour and thereby define a backset. Successively younger laminae appear to overstep the topographic high in front of the scour and expand down-palaeocurrent into a convex-upward, down-pa- 


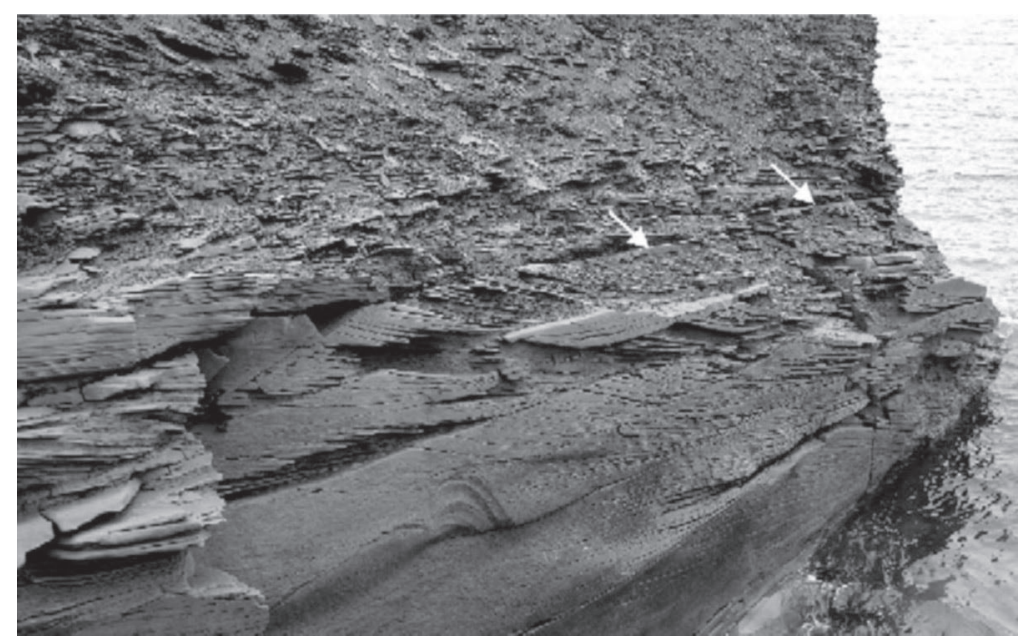

Figure 6. An example of a vertical succession showing progressive increase in flow velocity or Froude number. The lower part of the face shows large-scale cross-beds, the thickness of which decreases upward. Sets then become sigmoidal in cross-section as set thickness further decreases until the structure changes to flat lamination with minor convex-upward bedforms (possible antidunes) and lenses of structureless sandstone (white arrows). Late Carboniferous South Bar Formation, Stubberts Point, Nova Scotia, Canada. Cliff is c. $8 \mathrm{~m}$ high. Flow from left to right.

laeocurrent-climbing bedset. This is interpreted as a large-scale chute and pool structure that produced a large-scale antidune immediately downstream of the pool. Thus, in this case, the shallowest, upstream portion of the chute was a standing wave environment due to the hydraulic drop that would have been formed in this setting. Cross-sectional bedding geometry is quite similar to the "Type I and II dunes" of Schmincke et al. (1973) that were interpreted as chute and pool structures. A further possible example is illustrated in Figure 4B, which shows a sigmoidal backset within the Carboniferous Shepody Formation, developed up-palaeocurrent from a convex-upward bed surface onto which it was evidently accreting. In this case as in the last, palaeocurrent directions can be established independently from dune cross-bedding in adjacent strata.

\section{Fluvial lithosomes dominated by transitional upper flow regime and upper flow regime structures}

Given that some of the sedimentary structures described above may not have been recognized as upper flow regime structures, it is not surprising that few examples of sand-dominated, large-scale, upper flow regime architectural elements have been described in the literature beyond the "Laminated Sand Sheets" of Miall (1985). However, it is suggested here that such architectural elements are in fact widespread, and particularly so in certain types of fluvial succession, and that they preserve a wider range of sedimentary structures than merely flat lamination. Accordingly, modification of Miall's (1985) "Laminated Sand Sheets" (LS) element into a more broadly-defined "Upper Flow Regime
Sheets, Lenses and Scour Fills" element (UFR) is herein proposed. Two examples of such elements are described and interpreted where the lateral extent of outcrop allows establishment of cross-sectional geometry in two dimensions, and one example of a vertical succession where progressive upward changes in preserved structure allow interpretation of changing hydrodynamic and other environmental conditions.

\subsection{South Bar Formation at Victoria Mines, Nova Scotia, Canada}

The type section of the Upper Carboniferous South Bar Formation lies along the eastern shore of Sydney Harbour, Nova Scotia, from near South Bar to Victoria Mines (Rust and Gibling, 1990b). The uppermost part of the unit was examined as part of this study, and found to contain numerous examples of UFR elements. Indeed, UFR appears to be the dominant constituent of the several alluvial sandstone bodies examined. One such body is illustrated in cross-section in Figure 5A, and shows a sheet-like body composed of flat- and low-angle-laminated, flaggy sandstones. In detail, many of those structures are of the character interpreted herein as antidunes and transitional plane bed-antidunes.

\subsection{Colinlea Sandstone near Springsure, Queensland, Australia}

A road cutting on the Dawson Developmental Road some $20 \mathrm{~km}$ west of the town of Springsure, central Queensland, Australia, exposes the early Late Permian 
Colinlea Sandstone. The cutting, in the lowermost part of the formation, was interpreted by McLoughlin (1993) and Fielding et al. (1996) as being of fluvial origin. Here, the lateral relationships among interbedded cross-bedded sandstones (Miall's SB element, dominantly) and UFR elements is well-displayed. Discrete intervals are dominated by low-angle cross-bedding that passes downdip into flat lamination, more extensive intervals of flat lamination, convex-upward bedding structures, and the interpreted chute and pool structure described in Section 2.6 (Figure 5B). The base of the UFR element comprises a series of overlapping erosion surfaces that define a series of regularly-spaced highs and intervening scours (interpreted respectively as chutes and pools).

\subsection{South Bar Formation at Stubbert's Point, Nova Scotia, Canada}

The uppermost portion of the Upper Carboniferous South Bar Formation (Rust and Gibling, 1990b) is exposed at Stubberts Point, Sydney Mines, Atlantic Canada (Figure 6). An $8 \mathrm{~m}$ high cliff that forms the Point is composed of a single fluvial channel body that shows progressive upward change in preserved sedimentary structures. The lowermost part of the exposed section comprises cross-sets up to $1 \mathrm{~m}$ thick with slightly asymptotic foreset bases. Upward, set thickness decreases progressively, foreset dip decreases concomitantly, and ultimately the foreset geometry becomes more sigmoidal. Towards the top of the face, a transition to a flaggy bedding character reflects a further change to smallscale, low-angle cross-strata, convex-upward bedsets similar to those described by Rust and Gibling (1990a) at precisely the same stratigraphic horizon elsewhere, and thin, wedge-like or sheet-like beds of massive fine- to medium-grained sandstone (Figure 6). The section ultimately passes upward into predominantly ripple crosslaminated sandstones and hence into heterolithic facies of the overlying Sydney Mines Formation (Gibling and Bird, 1994).

This vertical facies succession is interpreted as the consequence of progressive and probably rapid aggradation in a large alluvial channel, such that initially dune phase conditions abruptly became transitional into plane bed conditions and hence into antidune conditions as water depth shallowed. The vertical succession of sedimentary structures cannot be explained in terms of waning flow, but can be satisfactorily explained by invoking progressive infilling of a single channel. That these structures are well-preserved can be attributed perhaps to the rapid rate of sediment aggradation, and the position of this body at the top of the sand-dominated South Bar Formation suggests that it records the rapid, final infilling of the braided fluvial channels of that time (Rust and Gibling, 1990b).

\section{Discussion}

Given the examples described and illustrated both here and in other literature, it is clear that the newly-defined UFR element is widely distributed among ancient fluvial systems. However, since UFR elements are nonetheless significantly less common than other architectural elements in the total volume of preserved fluvial strata, the question arises as to the circumstances that might favour the formation and preservation of this distinctive type of fluvial deposit.

1.
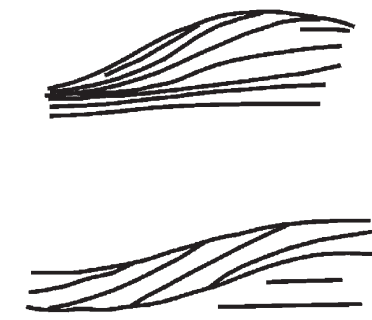

3.

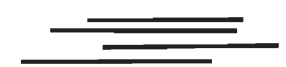

4.

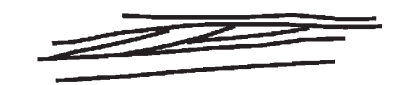

5.
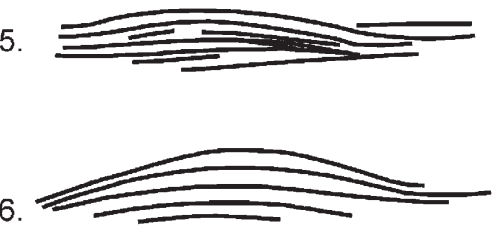

7.

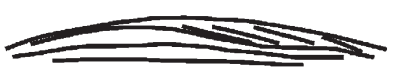

8.

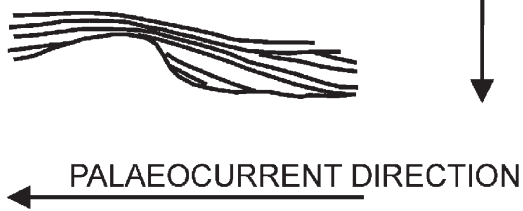

Figure 7. Line drawings to show an interpreted spectrum of sedimentary structures representative of the upper flow regime, from transitional dunes, through plane bed, transitional antidunes and antidunes, to chute and pool bedform states. Note that the drawings are intended to be scale-independent. Parting lineation is present on the bedding planes of many if not all of these structures. 
In modern fluvial environments, upper flow regime bedforms are preserved mainly in systems characterized by very rapid changes in flow stage, such that there is insufficient time during falling stage for the stream bed to re-equilibrate and rework those bedforms into lower flow regime bedforms (cf. Jones, 1977). Accordingly, deposits containing abundant upper flow regime structures in the rock record are commonly interpreted as the record of "ephemeral" systems. However, not all rivers that experience rapid stage fluctuations are ephemeral, indeed the dry and sub-humid tropics show exactly the type of hydrograph that would allow preservation of these structures. For example, Alexander and Fielding (1997) have described gravel antidunes and other high energy structures from the bed of the large, extremely variable discharge Burdekin River in north Queensland, Australia, the drainage basin of which lies in the dry tropics and is affected by summer monsoonal and cyclonic rainfall.

Given this, the thickness of some of the described examples, and other palaeoenvironmental data associated with these formations, it is clear that the association between upper flow regime structures and "ephemeral" environments must be broadened. All of the examples cited in this study are from successions where independent evidence indicates a strongly seasonal palaeoclimate, with a pronounced seasonal peak in precipitation, and hence runoff. The Carboniferous examples from Nova Scotia are thought to have been formed under strongly seasonal (possibly monsoonal) tropical climates (Calder, 1998), while the Permian example from Queensland is thought to have formed in a strongly seasonal, cool temperate setting (McLoughlin, 1993).

The common link between all of these examples, modern and ancient, is a strongly seasonal climate or palaeoclimate with a pronounced seasonal peak in precipitation and hence runoff. Accordingly, it is suggested that preservation of extensive UFR architectural elements in fluvial strata may be significantly enhanced by strongly seasonal palaeoclimates.

\section{Conclusions}

Transitional upper flow regime and upper flow regime sedimentary structures are inadequately described from the rock record, but may be moderately common among fluvial strata. Among these structures are 1) humpback, sigmoidal and low-angle cross-bedding, characteristic of the transition between the dune and upper plane bed stability field; 2) planar/flat lamination with parting lineation, characteristic of the upper plane bed phase; 3) flat and low-angle lamination with minor convex-upward elements, characteristic of the transition from upper plane bed to antidune stability fields;
4) convex-upward bedforms, down- and up-palaeocurrent-dipping, low-angle cross-bedding and symmetrical drapes, interpreted as the product of the antidune stability field; and, 5) backsets terminating updip against an upstream-dipping erosion surface, interpreted as recording chute and pool conditions. This spectrum of structures, summarized in Figure 7, is interpreted in terms of broadly increasing flow strength, and is consistent with the observations of Cheel (1990) from flume experiments in upper flow regime conditions.

Discrete bodies dominated by upper flow regime structures are quite common among certain types of fluvial successions, and accordingly a broadening of $\mathrm{Mi}$ all's (1985) "Laminated Sand Sheet" architectural element into an Upper Flow Regime Sheets, Lenses and Scour Fills element is proposed. Since the preservation of upper flow regime sedimentary structures is favoured under hydrological conditions characterized by abrupt drops in flow stage, it seems that abundant preservation of this element in a succession may have palaeoclimatic significance, and specifically may point to a climatic regime in which a pronounced seasonal maximum in precipitation and runoff was experienced.

Acknowledgments - Field data for this project have been collected over a long period and in the company of many collaborators. I particularly wish to acknowledge Mike Rygel and Martin Gibling for an introduction to the Carboniferous section of the Maritimes Basin in Nova Scotia, and Jan Alexander and Richard Breakspear for discussions on upper flow regime structures. Richard Breakspear is also thanked for allowing the use of two of his unpublished photographs in this paper. I thank the Editors, Octavian Catuneanu and Patrick Eriksson for the opportunity to participate in this special issue of Sedimentary Geology, and Phil Fralick and Bill Galloway for constructive reviews of the submitted manuscript.

\section{References}

Alexander and Fielding, 1997 - J. Alexander and C. R. Fielding, Gravel antidunes in the tropical Burdekin River, Queensland, Australia, Sedimentology 44 (1997), pp. 327-337.

Alexander et al., 2001 • J. Alexander, J. S. Bridge, R. J. Cheel, and S. F. LeClair, Bedforms and associated sedimentary structures formed under supercritical water flows over aggrading sand beds, Sedimentology 48 (2001), pp. 133-152.

Allen, 1982 - J. R. L. Allen, Sedimentary Structures, Developments in Sedimentology vol. 30, Elsevier, Amsterdam (1982) 593 and 663 pp.

Best and Bridge, 1992 • J. L. Best and J. S. Bridge, The morphology and dynamics of low amplitude bedwaves upon upper stage plane beds and the preservation of planar laminae, Sedimentology 39 (1992), pp. 737-752. 
Blair, 1987 - T. C. Blair, Sedimentary processes, vertical stratification sequences, and geomorphology of the Roaring River alluvial fan, Rocky Mountain National Park, Colorado, J. Sediment. Petrol. 57 (1987), pp. 1-18.

Brennand, 1994 - T. A. Brennand, Macroforms, large bedforms and rhythmic sedimentary sequences in subglacial eskers, south-central Ontario: implications for esker genesis and meltwater regime, Sediment. Geol. 91 (1994), pp. 9-55.

Bridge, 1993 - J. S. Bridge, Description and interpretation of fluvial deposits: a critical perspective, Sedimentology 40 (1993), pp. 801-810.

Bridge, 2003 - J. S. Bridge, Rivers and Floodplains: Forms, Processes, and Sedimentary Record, Blackwell, Oxford (2003) 489 pp.

Bridge and Best, 1988 • J. S. Bridge and J. L. Best, Flow, sediment transport and bedform dynamics over the transition from dunes to upper-stage plane beds: implications for the formation of planar laminae, Sedimentology 35 (1988), pp. 753-763.

Brierley, 1996 - G. J. Brierley, Channel morphology and element assemblages: a constructivist approach to facies modeling. In: P. A. Carling and M. R. Dawson, Editors, Advances in Fluvial Dynamics and Stratigraphy, Wiley, Chichester (1996), pp. 263-298.

Browne and Plint, 1994 - G. H. Browne and A. G. Plint, Alternating braidplain and lacustrine deposition in a strikeslip setting: the Pennsylvanian Boss Point Formation of the Cumberland Basin, Maritime Canada, J. Sediment. Res. B64 (1994), pp. 40-59.

Calder, 1998 - J. H. Calder, The Carboniferous evolution of Nova Scotia. In: D. J. Blundell and A. C. Scott, Editors, Charles Lyell: The Past is the Key to the Present, Spec. Publ. Geol. Soc. London vol. 143 (1998), pp. 261-302.

Chakraborty and Bose, 1992 - C. Chakraborty and P. K. Bose, Ripple/dune to upper stage plane bed transition: some observations from the ancient record, Geol. J. 27 (1992), pp. 349-359.

Cheel, 1990 - R. J. Cheel, Horizontal lamination and the sequence of bed phases and stratification under upperflow-regime conditions, Sedimentology 37 (1990), pp. 517-529.

Cotter and Graham, 1991 • E. Cotter and J. R. Graham, Coastal plain sedimentation in the late Devonian of southern Ireland: hummocky cross-stratification in fluvial deposits?, Sediment. Geol. 72 (1991), pp. 201-224.

Fielding and Webb, 1996 - C. R. Fielding and J. A. Webb, Facies and cyclicity of the Late Permian Bainmedart Coal Measures in the northern Prince Charles Mountains, MacRobertson Land, Antarctica, Sedimentology 43 (1996), pp. 295-322.

Fielding et al., 1996 - C. R. Fielding, J. Kassan, and J. J. Draper, Geology of the Bowen and Surat Basins, eastern Queensland, Australasian Sedimentologists Group Field Guide Series vol. 8, Geological Society of Australia, Sydney (1996) 126 pp.
Fielding et al., 2000 • C. R. Fielding, R. Sliwa, R. J. Holcombe, and J. Kassan, A new palaeogeographic synthesis of the Bowen Basin of central Queensland. In: J. Beeston, Editor, Bowen Basin Symposium 2000 Proceedings, Geological Society of Australia Coal Geology Group, Rockhampton (2000), pp. 287-302.

Fralick, 1999 - P. Fralick, Paleohydraulics of chute-and-pool structures in a Paleoproterozoic fluvial sandstone, Sediment. Geol. 125 (1999), pp. 129-134.

Gibling and Bird, 1994 - M. R. Gibling and D. J. Bird, Late Carboniferous cyclothems and alluvial paleovalleys in the Sydney Basin, Nova Scotia, Geol. Soc. Amer. Bull. 106 (1994), pp. 105-117.

Hand and Bartberger, 1988 • B. M. Hand and C. E. Bartberger, Leeside sediment fallout patterns and the stability of angular bedforms, J. Sediment. Petrol. 58 (1988), pp. 33-43.

Harms et al., 1975 • J. C. Harms, J. B. Southard, D. R. Spearing, and R. G. Walker, Depositional Environments as Interpreted from Primary Sedimentary Structures and Stratification Sequences, Short Course Notes vol. 2, SEPM, Tulsa, OK (1975) 161 pp.

Jones, 1977 • C. M. Jones, Effects of varying discharge regimes on bed-form sedimentary structures in modern rivers, Geology 5 (1977), pp. 567-570.

Jopling and Richardson, 1966 - A. V. Jopling and E. V. Richardson, Backset bedding developed in shooting flow in laboratory experiments, J. Sediment. Petrol. 36 (1966), pp. 821-824.

Jopling and Walker, 1968 - A. V. Jopling and R. G. Walker, Morphology and origin of ripple-drift cross-lamination, with examples from the Pleistocene of Massachusetts, J. Sediment. Petrol. 38 (1968), pp. 971-984.

Kennedy, 1963 - J. F. Kennedy, The mechanics of dunes and antidunes in erodible-bed channels, J. Fluid Mech. 16 (1963), pp. 521-544.

Langford and Bracken, 1987 - R. Langford and B. Bracken, Medano Creek, Colorado, a model for upper-flow-regime fluvial deposition, J. Sediment. Petrol. 57 (1987), pp. 863-870.

Leclair and Bridge, 2001 - S. F. Leclair and J. S. Bridge, Quantitative interpretation of sedimentary structures formed by river dunes, J. Sediment. Res. 71 (2001), pp. 713-716.

McKee et al., 1967 • E. D. McKee, E. J. Crosby, and H. L. Berryhill, Flood deposits, Bijou Creek, Colorado, J. Sediment. Petrol. 37 (1967), pp. 829-851.

McLoughlin, 1993 - S. McLoughlin, Plant fossil distributions in some Australian Permian non-marine sediments, Sediment. Geol. 85 (1993), pp. 601-619.

Miall, 1985 - A. D. Miall, Architectural-element analysis: a new method of facies analysis applied to fluvial deposits, Earth Sci. Rev. 22 (1985), pp. 261-308.

Miall, 1996 - A. D. Miall, The Geology of Fluvial Deposits: Sedimentary Facies, Basin Analysis and Petroleum Geology, Berlin, Springer-Verlag (1996) 582 pp.

Middleton, 1965 • G. V. Middleton, Antidune cross-bedding in a large flume, J. Sediment. Petrol. 35 (1965), pp. 922-927. 
Paola et al., 1989 - C. Paola, S. M. Wiele, and M. A. Reinhart, Upper-regime parallel lamination as the result of turbulent sediment transport and low-amplitude bedforms, Sedimentology 36 (1989), pp. 47-60.

Picard and High, 1973 - M. D. Picard and L. R. High, Sedimentary structures of ephemeral streams, Developments in Sedimentology vol. 17, Elsevier, Amsterdam (1973) 223 pp.

Røe, 1987 - S. -L. Røe, Cross-strata and bedforms of probable transitional dune to upper-stage plane-bed origin from a Late Precambrian fluvial sandstone, northern Norway, Sedimentology 34 (1987), pp. 89-101.

Røe and Hermansen, 1993 - S. -L. Røe and M. Hermansen, Processes and products of large, Late Precambrian sandy rivers in northern Norway. In: M. Marzo and C. Puigdefabregas, Editors, Alluvial Sedimentation, Spec. Publ. Int. Assoc. Sedimentol. vol. 17, Blackwell, Oxford (1993), pp. 151-166.

Russell and Arnott, 2003 - H. A. J. Russell and R. W. C. Arnott, Hydraulic jump and hyperconcentrated flow deposits of a glacigenic subaqueous fan: Oak Ridges Moraine, southern Ontario, J. Sediment. Res. 73 (2003), pp. 887-905.

Rust and Gibling, 1990a - B. R. Rust and M. R. Gibling, Three-dimensional antidunes as HCS mimics in a fluvial sandstone: the Pennsylvanian South Bar Formation near Sydney, Nova Scotia, J. Sediment. Petrol. 60 (1990), pp. 540-548.

Rust and Gibling, 1990b • B. R. Rust and M. R. Gibling, Braidplain evolution in the Pennsylvanian South Bar Formation, Sydney Basin, Nova Scotia, Canada, J. Sediment. Petrol. 60 (1990), pp. 59-72.

Saunderson and Lockett, 1983 - H. C. Saunderson and F. P. J. Lockett, Flume experiments and structures at the dune-plane bed transition. In: J. D. Collinson and J. Lewin, Editors, Modern and Ancient Fluvial Systems, Spec. Publ. Int. Assoc. Sedimentol. vol. 6, Blackwell, Oxford (1983), pp. 49-58.

Schmincke et al., 1973 - H. -U. Schmincke, R. V. Fisher, and A. C. Waters, Antidune and chute and pool structures in the base surge deposits of the Laacher See area, Germany, Sedimentology 20 (1973), pp. 553-574.

Shaw and Kellerhals, 1977 - J. Shaw and R. Kellerhals, Paleohydraulic interpretation of antidune bedforms with applications to antidunes in gravel, J. Sediment. Petrol. 47 (1977), pp. 257-266.

Simons et al., 1963 - D. B. Simons, E. V. Richardson, and D. F. Nordin Jr., Sedimentary structures generated by flow in alluvial channels. In: G. V. Middleton, Editor, Primary Sedimentary Structures and their Hydrodynamic Interpretation, Spec Publ vol. 12, SEPM, Tulsa, OK (1963), pp. 34-52.

Sneh, 1983 - A. Sneh, Desert stream sequences in the Sinai Peninsula, J. Sediment. Petrol. 53 (1983), pp. 1271-1280.

Southard and Boguchwal, 1990 - J. B. Southard and L. A. Boguchwal, Bed configurations in steady unidirectional flows. Part 2. Synthesis of flume data, J. Sediment. Petrol. 60 (1990), pp. 658-679.

Stear, 1985 - W. M. Stear, Comparison of the bedform distribution and dynamics of modern and ancient sandy ephemeral flood deposits in the southwestern Karoo region, South Africa, Sediment. Geol. 45 (1985), pp. 209-230.

Tunbridge, 1981 - I. P. Tunbridge, Sandy high-energy flood sedimentation: some criteria for recognition, with an example from the Devonian of SW England, Sediment. Geol. 28 (1981), pp. 79-96. 